\title{
LA INTERVENCIÓN PÚBLICA EN LAS SOCIEDADES COOPERATIVAS: LA NECESIDAD DE REVISAR EL MODELO DE "TUTELA ADMINISTRATIVA"
}

\author{
María Burzaco Samper \\ Profesora Propia Agregada de Derecho Administrativo \\ Facultad de Derecho (ICADE) \\ Universidad Pontificia Comillas \\ http://orcid.org/0000-0001-9875-0552
}

\section{RESUMEN}

El modelo de intervención pública que contienen las leyes cooperativas en España responde a un molde que tiene su origen en los antecedentes históricos. Asimismo, la multiplicidad normativa plantea una serie de dificultades que se manifiestan de diverso modo. Similares en su estructura, las leyes cooperativas conciben la presencia de las Administraciones Públicas como una balanza de contrapesos: por un lado, el fomento de las cooperativas; por otro, el control materializado en una serie de mecanismos de intervención de variable intensidad.

Esa importante presencia pública plantea dos problemas fundamentales: a) el difícil equilibrio con el principio de autonomía, que forma parte de la identidad cooperativa; b) las diferencias en el contenido de las leyes respecto de determinadas potestades especialmente intensas. Algunas de las leyes más recientes parecen incorporar una reflexión sobre algunas de estas modalidades interventoras. Sin embargo, son avances aún tímidos y no siempre coherentes con la regulación que contienen.

PALABRAS CLAVE: Identidad cooperativa, principio de autonomía, Administración Pública, intervención administrativa, fomento público, derecho sancionador.

CLAVES ECONLIT / ECONLIT DESCRIPTORS: H83, K23, K49, P13.

Cómo citar este artículo/How to cite this article: BURZACO SAMPER, M.: "La intervención pública en las sociedades cooperativas: la necesidad de revisar el modelo de 'tutela administrativa'", CIRIEC-España, Revista Jurídica de Economía Social y Cooperativa, n 39, 2021, pp. 97-134. DOI: 10.7203/CIRIEC-JUR.39.21404 


\section{PUBLIC INTERVENTION IN COOPERATIVES: THE NEED TO REVIEW THE "ADMINISTRATIVE TUTELAGE" MODEL}

\section{EXPANDED ABSTRACT}

The model of public intervention in cooperatives currently in place in Spain cannot be isolated from the historic evolution of the relevant regulations. This journey also explains the constitutional distribution of responsibilities for all matters relating to cooperatives, which forms the basis of the multi-layered legislative framework to be examined.

The path taken by the regulatory framework for cooperatives in Spain demonstrates:

a) Firstly, the strong ideological impact in the initial phases, which also undoubtedly had consequences for the positions maintained by the public authorities with regard to cooperativism; an integral factor in its connection to the workers' union movement and the different constructions relating to the relations between State and cooperativism. This explains why it has been so difficult for the cooperative formula to fit into the known regulatory moulds - a circumstance which is not unique to Spain.

b) On the other hand, the impossibility of isolating intervention in cooperatives from the general traits of public intervention in the economy that have characterised every period of history. In this regard, one can observe a certain coherence between them both, although it would not be correct to say that the treatment of cooperatives has been substantially different from the way in which the state has perceived its organisational role in each period.

c) Finally, a certain inertia in the maintenance of intervention mechanisms: thus, and despite the verifiable differences with regard to some aspects, there seems to be a common thread running through all the manifestations of that organisational activity (administrative registry, sanctioning powers, temporary intervention mechanisms, disqualification, etc.).

The link with the current legislation on cooperatives requires a reference to the Spanish Constitution for the following reasons: firstly, because of the mandate, provided for in Article 129/2 of the Spanish Constitution, to promote cooperativism through adequate legislation which must also be linked to the constitutional economic model and the principles of the social and democratic state. Another reason, however, is the impact that our intricate system by which responsibility is distributed has had on the current multi-layered legislative framework, characterised by multiple laws which, although they have some things in common, also differ in some not insignificant respects. This legislative multiplicity has resulted in phenomena such as the "flight from the law on cooperatives", according to the two realities that this phrase may refer to: a) the search for the legal system most favourable to the inter- 
(pp. 97-134)

ests of those establishing cooperatives; b) the avoidance of any regional laws that would be applicable, either in favour of state law or other more favourable regional legislation.

The study of regional legislation highlights the fact that the various rules share some common features:

a) Respect, at least in their formal wording, for the principles of cooperativism and the singular nature of cooperatives. Such principles would make it possible both to differentiate cooperatives from other forms of business and to differentiate "false" cooperatives from "authentic" ones. Nevertheless, and despite the paradox that this entails, the preciseness of said principles is intended to render them compatible with a certain degree of flexibility in their regulatory incorporation.

b) The laws appear to create a balance of counterweights; thus, the general mandate to promote cooperativism (which materialises in incentives of varying nature) coexists with a system of intervention aimed at preventing the cooperative formula from being employed in a self-interested or dishonest manner, or serving to avoid requirements provided by certain sector-specific regulations (tax, employment, etc.).

That difficult balance required of the public authorities is best exemplified by ILO Recommendation 193, and projects onto the principle of cooperative autonomy.

In more detail, the study analyses the provisions in place on both sides of the scale:

a) As regards promotion, it demonstrates the tendency for grandiose proclamations of little real effectiveness, although curious differences can be found in the formulas used depending on how recent, or otherwise, the laws in question are.

Such general declarations are accompanied by concrete measures, most of which have been inherited from past laws.

In that same context, there is the activity of promoting cooperativism linked to areas such as education and public procurement. The importance of these sectors which should not be overstated, because the measures contemplated in the laws on cooperatives are faced with serious obstacles regarding their application due to their overlapping with provisions of sector-specific legislation with which they are incompatible (the law on public procurement, for example).

b) In relation to interventional or organisational activities, the legislatively established mechanisms are also examined:

1) Registry procedure, characterised by evolution towards an administrative registry model which, however, emulates the Commercial Register and its principles (an aspect which is of doubtful constitutionality). 
2) The cooperative inspectorate, with coexists with inspection activities in the relevant industry. In this regard, there are again overlaps which add to the discrepancy between the appropriate model and the pertinence (or otherwise) of an inspectorate specific to cooperatives.

3) The penalty system, which constitutes an important part of the rules regarding public administrations and cooperativism. This point is of singular importance for two reasons: firstly, one observes a refinement of the penalty system in its adherence to the principle by which criminal offences must fall within a prior definition, thus defining violations more accurately (as well as preventing excessively open or ambiguous definitions), and defining penalties more precisely. This consideration does not preclude the existence of aspects that are open to criticism, such as the residual definitions that remain in place for minor offences.

Nevertheless, the most concerning aspect is the legislative disparity: a comparison between the several laws on cooperatives highlights unreasonable differences between the statutes of limitation for aspects such as offences and penalties, the amounts of said penalties, or the very acts defined as offences, inter alia.

c) Disqualification, a measure which is linked to both the reasons for winding up of cooperatives and the commission of serious and/or very serious offences, although its regulation is not always sufficiently precise.

d) Temporary intervention, a copy of corporate intervention transposed into the legislation on cooperatives, although only enshrined in two cooperative-specific laws.

The evolution of regional legislation on cooperatives offers certain signs which make it possible to discern that the legislators appear to be re-establishing their traditional role and the pertinence of reviewing the relational model in place between public authorities and cooperatives. Thus, for example, the Region of Extremadura's Stated Purpose behind Law 9/2018, of 30 0ctober 2018, on cooperatives, alludes to an intended reduction of the penalty system "which, in the future, will probably disappear". The Basque legislator also acknowledges "the need to innovate aspects which have to a certain extent become obsolete" - one of these being "the 'policing' role played by the authorities", and that "it is a tributary of a regulation anchored to a vision of administrative tutelage and supervision which is understood to be in need of review" (Stated Purposes of Law 11/2019, of 20 December 2019, on Basque Cooperatives). Nonetheless, these changes are still in their incipient stages, showing how difficult it is to break with the inertia of the historical regulatory framework.

KEYWORDS: Cooperative identity, principle of autonomy, public administration, administrative intervention, public promotion, sanctioning law. 


\section{SUMARIO}

I. Breves apuntes sobre las relaciones Estado-cooperativismo en España. Perspectiva histórica. 1. La incidencia del factor ideológico. 2. El molde normativo aplicado a las cooperativas. 3. Un esbozo de la importancia de la Constitución Española de 1978. II. El principio de autonomía cooperativa en la actualidad y su traslación en las leyes cooperativas vigentes. 1. Legislación adecuada y protagonismo de los principios cooperativos. 2. Principio de autonomía y fomento público del cooperativismo. III. El modelo de intervención pública en la legislación cooperativa. 1. Esquema del marco normativo común. 2. Principio de fomento del cooperativismo y su materialización. 3. La actividad de ordenación o intervención: las medidas de control de la legalidad. 4. ¿Hacia una reconsideración del papel de las Administraciones Públicas? Algunos tímidos indicios y sus paradojas. IV. Conclusiones. Bibliografía.

\section{Breves apuntes sobre las relaciones Estado- cooperativismo en Espańa. Perspectiva histórica}

El escenario normativo que caracteriza el Derecho Cooperativo en Espańa no puede separarse del componente histórico: en primer lugar, porque el nacimiento y evolución de la legislación cooperativa explican el escenario mismo y sus paradojas; $y$, de otro lado, porque determinados rasgos -singularmente los referidos a la intervención pública- siguen manifestándose en las leyes actuales en una suerte de inercia de la que está costando desprenderse. De ello daremos cuenta brevemente:

\section{La incidencia del factor ideológico}

Las complejas relaciones entre Estado y Movimiento cooperativo han dado pie a una prolija literatura, quizás más política que propiamente jurídica. Un hecho que se justifica, al menos parcialmente, desde la contemplación de las bases dogmáticas de la cooperación y su consideración como sistema superador del capitalismo clásico. El engarce del cooperativismo con la Revolución industrial y el movimiento obrero revolucionario (Valdés Dal-Ré, 1975:43) ${ }^{1}$ constituyen el necesario punto de conexión con la referida vertiente teórica, distinguiéndose dos posiciones fundamentales y convirtiéndose, además, en ingrediente esencial del análisis histórico (Drimer \& Kaplan de Drimer, 1981:484-487):

1. Habla de "identidad genética" entre los movimientos cooperativo y asociativo obrero. 
a) La "restrictiva", representada por aquellos autores que reclaman la total independencia del Estado, sin aceptar ningún tipo de intervención pública, sea de signo positivo o negativo. Corresponde a los primeros estadios del desarrollo cooperativo en los que imperaban los recelos ante la actitud paternalista estatal.

b) La "realista" que, sin renunciar a la autonomía cooperativa, advierte la necesidad de colaborar en las tareas que realiza el Estado. Esta postura nacería como consecuencia del incremento de funciones propio del Estado moderno, consolidándose a partir de la crisis de 1929 y de la II Guerra Mundial.

Aunque este trabajo no va a abordar un examen pormenorizado de los antecedentes $^{2}$, debemos esbozar sus bases más relevantes en la medida en que permiten explicar el marco actual:

El inicio del cooperativismo español se vio fuertemente mediatizado por diversos factores impregnados de un notable componente ideológico. Las reticencias ante esta figura novedosa que era la "cooperativa", el desconocimiento de sus caracteres propios o la dificultad de hallarle el oportuno encuadramiento en las instituciones jurídicas conocidas fueron algunos de esos factores que dieron como resultado su tardío e imperfecto tratamiento normativo.

El estudio de la legislación histórica es una carrera de obstáculos, con vaivenes constantes marcados por la paradoja de una postura pública marcada por el temor al movimiento cooperativo (al que trata con prevención), admitiendo, al mismo tiempo, las bondades de las cooperativas en determinados sectores de actividad.

La visión crítica que suele acompañar a los antecedentes debe, sin embargo, matizarse: en primer lugar, porque, como cualquier otra fórmula novedosa, generó problemas de encaje en los moldes existentes en sus orígenes (lo que explica, por ejemplo, su ubicación en la legislación de asociaciones). Dificultad acrecentada por lo que se reconoce como polimorfismo del fenómeno cooperativo, en el que se distinguen tres vertientes (Mateo Blanco, 1985:41):

\section{Un plano ideológico: Principios que componen doctrina que origina un movi- miento.}

2. Un plano social: Individuos que se unen, asociándose.

3. Un plano económico: la existencia de unas necesidades de esos individuos que les mueven a aquella unión por su interés para formar una empresa ${ }^{3}$.

2. Sobre esta cuestión, vid. BURZACO SAMPER, 2015a; y bibliografía allí citada.

3. Esta diferenciación se trasladaría también a la distinción entre términos afines. En este sentido, Sanz Jarque (1983:7, 1994:14-16) apunta: "Se nos presentan las Cooperativas en la vida real, en múltiples manifestaciones: 
Esta intersección de planos -económico, sociológico, político, jurídico-se revela asimismo en los múltiples criterios clasificatorios manejados por la doctrina en su empeño por emprender la tarea de categorizar etapas en la conformación del derecho cooperativo ${ }^{4}$.

Los procesos políticos que trazan la historia de Espańa se proyectan asimismo en la normativa cooperativa; circunstancia que, en ocasiones, se olvida en los análisis que aíslan la injerencia en las cooperativas de los rasgos generales de la intervención administrativa económica propia de cada momento histórico. El estudio de la regulación desde una visión más amplia demuestra que los mecanismos de intervención pública son coherentes con el modelo imperante en cada momento. Así, por ejemplo, la intensa intervención pública en la actividad económica privada característica de la época republicana se refleja asimismo en las cooperativas, sin perjuicio de que lo extremo del régimen que habría de sucederle terminara diluyendo esa realidad. De la misma manera, en la etapa franquista, los mecanismos de intervención totalizadora marcados por la confluencia de instancias administrativas y organización sindical se proyectan con carácter general, y no sólo para las cooperativas.

El componente ideológico del cooperativismo es asimismo un factor influyente, máxime cuando en algunas etapas el signo de las cooperativas varía en función de su actividad y lugar de implantación ${ }^{5}$.

Por lo demás, no es tampoco exclusiva de nuestro país la tardanza en conseguir una legislación acorde con la institución (Colombain, 1956:136); máxime cuando la demora en el desarrollo de la Revolución industrial en España explica la también más tardía aparición del proletariado (Alarcón Caracuel, 1975:50).

como entidades societarias y empresariales típicas: las propiamente cooperativas; como organización propia y especial, la Organización cooperativa que disciplina y defiende aquellas de modo colectivo; y como doctrina, principios y normas o legislaciones especiales, el Movimiento cooperativo, que fundamentan, matizan y rigen las cooperativas de modo propio y diferente de los entes societarios y empresariales anteriormente conocidos. En conjunto, todo ello constituye una serie típica de relaciones económico-sociales y jurídicas, de organización, y de doctrina, principios y normas, que son consustanciales a la estructura vigente de la Comunidad y del Estado y forman una nueva institución de la vida social".

4. Sin ánimo agotador, los criterios clasificatorios manejados van desde el enfoque situado en la naturaleza jurídica de las cooperativas y la autonomía de la regulación cooperativa (v. gr. Polo, 1942:214-215; Del Arco Álvarez, 1963:199-200; Gadea Soler, 1994:101-102); hasta los principios de organización del Estado (VICENT CHULIÁ, 1972:465-466), pasando por otras que centran su atención en el marco global del Movimiento cooperativo (SANZ JARQUE, 1974:12-13; Joaniquet Aguilar, 1965:3 y ss.)

Sobre las dificultades dogmáticas del concepto de sociedad cooperativa, vid. Gadea Soler, 2012:3 y ss.

5. Así, en los inicios del siglo XX se tendió a proteger el cooperativismo agrario; y durante los años de la dictadura de Primo de Rivera trató de impulsarse el cooperativismo de consumo de los empleados civiles y militares o las llamadas cooperativas de casas baratas. La República, hostil al cooperativismo agrario por su sesgo confesional católico, primó el cooperativismo obrero de consumo y producción (Del Arco Álvarez, 1977:36). 
Finalmente, los lazos del cooperativismo inicial con el movimiento asociativo obrero explican que compartieran bases ideológicas con el socialismo utópico de Fourier, Owen... (Gide, 1944:44), así como su apariencia de "movimiento subversivo" (Divar Garteiz-Aurrecoa, 1987:8). Dicho esto, las reivindicaciones del movimiento obrero, lejos de canalizarse por una única vía, encontraron tres caminos, inicialmente complementarios y confusos en sus contornos (Aranzadi Tellería, 1988:34-35), que fueron singularizándose: mutualismo, cooperativismo y sindicalismo. Con todo, la relación entre estas tres ramas distó de ser pacífica y perjudicó la concepción que, desde el poder público, se tenía de la cooperación.

\section{El molde normativo aplicado a las cooperativas}

El tránsito por la legislación cooperativa española pasa por etapas diversas (Burzaco Samper, 2015a:21 y ss.) marcadas por la búsqueda de una legislación propia que, aparentemente alcanzada con la Ley Republicana de 1931, ha tenido consecuencias determinantes en la situación actual. Hemos afirmado reiteradamente que, a nuestro juicio, el factor que más ha influido en el devenir de la legislación cooperativa por vía negativa fue su exclusión del Código de Comercio de 1885 que, por otro lado, no sólo afectó a las cooperativas sino que, como ha evidenciado reputada doctrina, supuso un disloque del concepto mismo de Derecho Mercantil (Garrigues, 1959:10, 21, 39, 49; Vicent Chuliá, 1976:78).

Desde el punto de vista de las potestades administrativas sobre las cooperativas, podemos afirmar que, si bien cada etapa ha aportado su grano de arena, el molde actual se reconoce con más claridad en la ley republicana; norma que en la Exposición de Motivos recoge expresiones reveladoras:

(...) al Estado toca fomentar y, sobre todo, encauzar. Habrá de hacerse intensa labor difundiendo el conocimiento de los hechos, los principios y la técnica de la cooperación. Habrá de darse a las cooperativas genuinas el justo trato tributario, según el grado de utilidad social. Habrá de llegarse al auxilio directo, cuando esté justificado (...)

Esa dualidad de fomento-control coloca en manos del poder público intensos mecanismos de intervención, inspección y sanción, convirtiéndolo en una suerte de garante de la pureza cooperativa llamado a deslindar las cooperativas auténticas de las mixtificadas o simuladas. Una situación que, además, debe contextualizarse en un régimen caracterizado por la amplia intervención en la actividad económica privada (Martín-Retortillo Baquer, 1989:711). 
Las cooperativas bajo la dictadura franquista merecerían un capítulo aparte del que ya se ha escrito sobradamente y que muestra un sistema de controles llevado al extremo, abiertamente incompatible con la autonomía cooperativa ${ }^{6}$, y en el que no procede detenerse ahora so pena de desenfocar nuestro objeto de estudio.

\section{Un esbozo de la importancia de la Constitución Espańola de 1978}

Más interesa la aparición de la CE de 1978 en la triple dirección que dejaremos apenas esbozada para servir de enlace con el siguiente apartado:

a) Si, como decíamos, el polimorfismo del fenómeno cooperativo coadyuvó a una regulación insatisfactoria del mismo por el protagonismo perturbador que adquirieron los aspectos político-ideológicos, puede decirse que la CE cierra ese marchamo. Desprendido ya de ambiciones utópicas del pasado, la CE enfoca la cooperación como realidad económico-social y atiende a las sociedades cooperativas como empresas con el valor añadido de su funcionalización hacia objetivos de carácter social.

b) La circunstancia anterior explica que el cooperativismo en perspectiva constitucional no puede limitarse a la mención puntual del art. 129.2 $\mathrm{CE}^{7}$ (por importante que sea éste), sino que debe conectarse con el modelo económico constitucional y con los principios de Estado Democrático y Estado Social.

c) Cobra singular relevancia la fórmula estructural que brinda nuestro Estado compuesto y su característico e intrincado sistema de distribución de competencias económicas. Con el correr del tiempo, esta cuestión ha pasado a un indiscutible primer plano y sólo desde ella se explica la actual situación.

Tales vertientes son las que han dado contenido al "fomento de las sociedades cooperativas mediante una legislación adecuada” empleada en el art. 129.2 CE:

1) La idea inicial pasó por entender que la $C E$ estaba reclamando una nueva ley de cooperativas que rompiera con el régimen anterior, pero sin otra pretensión que conseguir un marco regulatorio idóneo ${ }^{8}$.

6. En este punto nos remitimos a BURZACO SAMPER, 2015a:53 y ss.

7. Sobre las razones detrás de este precepto, vid. PANIAGUA ZURERA, 1997:161; FAJARDO GARCÍA, 2018.

8. Esta inicial interpretación se basa en el art. 119.1 del anteproyecto recogía la siguiente dicción: "Los poderes públicos promoverán eficazmente las diversas formas de participación en la empresa y facilitarán un marco legislativo adecuado para las empresas cooperativas". 
2) Otras interpretaciones, combinando la idea de fomento y legislación adecuada, abogaban por una normativa "promotora, impulsora y protectora" de la que derivarían dos consecuencias inmediatas: la prohibición de discriminación (Paz Canalejo, 1980:79) y la obligación de que la regulación que hubiera de darse contuviera mecanismos públicos de fomento que privilegiaran la fórmula cooperativa sobre cualesquiera otras (Montolío, 1993:128).

Puede decirse que esta interpretación ha terminado por imponerse y, lo que es más importante, ha encontrado concreción normativa en una suerte de principio general por el que fomento y promoción del cooperativismo se erige en tarea de interés público. Como analizaremos en su momento, tal principio se incorpora invariablemente en las leyes vigentes, presidiendo los títulos que, con alguna oscilación en las denominaciones, regulan la relación entre Administración Pública y cooperativas.

3) La genérica llamada a los poderes públicos del art. 129.2 CE derivó en una consecuencia que cabe calificar de inesperada y que, por otro lado, es inseparable del complejo entramado que caracteriza nuestra distribución constitucional de competencias. La inexistencia de mención expresa a las cooperativas en los arts. 148 y 149 CE sirvió de fundamento para que algunas CCAA asumieran estatutariamente la competencia para dictar la regulación sobre estas sociedades: así, y con base en una reivindicada autonomía del Derecho Cooperativo, éste se convierte en "materia" separable de otros títulos, escisión que lleva como última consecuencia a su entendimiento como materia competencial con sustancia propia que, a su vez, y al no estar expresamente prevista en el art. 149.1 CE, podía ser acogida por los Estatutos de Autonomía dentro de los límites que las vías de acceso imponían originariamente. Los problemas empiezan a surgir cuando la Comunidad Autónoma vasca se adelanta al legislador estatal dictando la primera Ley de cooperativas postconstitucional; ley que, siendo objeto de recurso de inconstitucionalidad, da pie al primer pronunciamiento del TC sobre esta cuestión en STC 72/1983, de 29 de julio. Esta Sentencia pasó de puntillas sobre la naturaleza de las empresas cooperativas, viniendo a legitimar la regulación autonómica con base en una competencia exclusiva cuyos linderos, sin embargo, quedaban sin definir claramente y que, observando la normativa actual, ha adquirido una fuerza expansiva inusitada.

De este modo, el art. 129.2 CE terminó por rebasar las fronteras que su propia ubicación sistemática permite pasando a ser lo que sólo puede enjuiciarse como inadecuado título competencial y reabriendo así, de algún modo, el debate sobre la naturaleza de las empresas cooperativas. 
Por otro lado, la doctrina ha venido advirtiendo con inquietud que la multiplicidad normativa puede propiciar una "huida del Derecho Cooperativo", expresión que, emulando la conocida sobre el Derecho administrativo, se interpreta con sentidos diversos: i) como búsqueda de formas de organización empresarial con un régimen jurídico más estable (Morillas Jarillo, 2002:4746); ii) como un "fenómeno de sorteo de la norma autonómica” (García-Gutiérrez Fernández, 1998:211), en favor ya de la ley estatal, ya tratando de encajar en la ley autonómica considerada más favorable (Pastor Sempere, 1999:152; Alfonso Sánchez, 1999:1689 [nota al pie no 72]).

Posiblemente tengan razón quienes opinan que es estéril el debate sobre el carácter mercantil de las cooperativas y la eventual reconducción de la competencia al Estado (Fajardo García, 2018:147). Cualquier otra solución es ciertamente política ficción -máxime recibido el aval de la jurisprudencia constitucional desde tiempos tempranos-, si bien podemos convenir en que el maremágnum regulador no es el escenario idóneo desde distintos puntos de vista ${ }^{9}$ y hay quien entiende que aquella polémica no está definitivamente cerrada.

\section{El principio de autonomía cooperativa en la actualidad y su traslación en las leyes cooperativas vigentes}

\section{Legislación adecuada y protagonismo de los principios cooperativos}

Sin lanzarnos al debate sobre cuál es el contenido del término "legislación adecuada" e, incluso, sobre el modelo de legislación ${ }^{10}$, hay apreciable consenso sobre la exigencia de que aquella sea respetuosa con los principios cooperativos y acorde con su naturaleza específica ${ }^{11}$. Requerimiento éste plenamente coherente con la configu-

9. MOZAS MORAL (2018:115) pone de relieve que los legisladores, en su afán por regular sus peculiaridades, han encorsetado las sociedades cooperativas y obstaculizan el principio de intercooperación.

PANIAGUA ZURERA y JIMÉNEZ ESCOBAR (2014:69) han propugnado una ley de armonización como solución más razonable.

10. Vid. CONFERENCIA INTERNACIONAL DEL TRABAJO [CIT], 2001:87. En este documento se distinguen hasta seis "formas de legislación cooperativa": a) Ley general de cooperativas, reguladora de los distintos tipos; b) Leyes concretas para tipos especiales de cooperativas (modalidad que está transformándose en un esquema de ley general y ley especial para cooperativas de crédito); c) Regulación en capítulos específicos de codificaciones más amplias; d) Disposiciones especiales enmarcadas en una ley organizativa general (el prototipo es la legislación anglosajona que incluye las cooperativas en la Industrial and Provident Societies Act); e) Inexistencia de legislación específicamente cooperativa (situación excepcional); f) Las modalidades de los países federales, que varía según la competencia sobre dicha legislación corresponda al Estado federal o a los Estados federados (pp. 86-87).

11. Por todos, vid. VICENT CHULIÁ, 1984:14. 
ración de tales principios como auténtica piedra angular del movimiento cooperativo, "único "prius" de rigidez [y] esencia de toda interpretación jurídica en la materia" (Divar Garteiz-Aurrecoa, 1986:135).

Por lo que a este punto interesa, debemos destacar dos cuestiones:

a) Como hemos puesto de relieve en otro lugar (Burzaco Samper, 2015b:9), los principios definen la esencia cooperativa y constituyen una pieza irrenunciable que actúa en una doble dirección: i) permitiendo diferenciar las cooperativas de cualquier otra forma de empresa (Prieto Juárez, 2002:131); ii) separando las "falsas" y "auténticas" cooperativas (Vergez Sánchez, 1973:17).

b) La rigurosidad y firmeza en los principios ha tratado de hacerse compatible con la flexibilidad en el modo de efectuar su incorporación normativa (St. Siegens, 1970:82).

En este orden de cosas, es primordial tener presente que el movimiento cooperativo representado en la ACI vive en constante proceso evolutivo y de reflexión; circunstancia que encuentra su razón de ser en la necesidad de adaptación a la realidad cambiante y que, por otra parte, determina variaciones periódicas y consiguientes reajustes tendentes a la actualización permanente de la normativa cooperativa.

La centralidad de los principios y valores cooperativos ha adquirido nueva fuerza en el Plan Estratégico de la Alianza Cooperativa Internacional 2020-2030 ${ }^{12}$, siendo su primer "tema clave" la promoción de la identidad cooperativa. En este sentido reconoce que la Declaración sobre la identidad cooperativa "es fundamental en el reconocimiento legislativo y regulatorio del carácter único del modelo cooperativo" y concreta en la iniciativa estratégica A.2. este aspecto ("Promover una legislación que proteja la identidad cooperativa"). La importancia de lo que gira en torno a esto se muestra elocuentemente en el próximo XXXIII Congreso Cooperativo Internacional que se celebrará en Seúl en diciembre de este 2021, bajo el título "Profundizando en la identidad cooperativa" ${ }^{3}$.

Con todo, el posicionamiento doctrinal requeriría de matices adicionales: así, las posturas que otorgan protagonismo a los principios, critican la excesiva flexibilidad de la normativa porque pueden terminar diluyendo aquellos (Marín Hita, 2020:14). Por el contrario, otros autores enfatizan la discrecionalidad del legislador en la confi- 
guración del régimen jurídico cooperativo, siendo los principios inspiración pero no presupuesto de su autenticidad ${ }^{14}$.

\section{Principio de autonomía y fomento público del cooperativismo}

Dejando al margen otros principios cooperativos, por lo que interesa a este trabajo destaca el principio de autonomía, conforme al cual:

Las cooperativas son organizaciones autónomas de autoayuda, gestionadas por sus miembros. Si establecen convenios con otras organizaciones, incluidos los gobiernos, o si reciben capital de fuentes externas, lo hacen en condiciones que garanticen la gestión democrática por parte de los miembros y respeten su autonomía cooperativa.

Ciertamente su contenido ha evolucionado en su sentido y trasfondo ${ }^{15}$. Los primeros tiempos del movimiento cooperativo estuvieron marcados por una fuerte impronta ideológica que influyó intensamente en su recorrido. Y esa misma huella trazaba el principio de autonomía en un sentido netamente político. El proceso de "normalización" de las relaciones del cooperativismo con el poder público aligeró también la carga adherida al principio y su significado, no pudiendo desvincularse de ciertos elementos:

La pertinaz reivindicación de fomento del cooperativismo y los mandatos que en este mismo sentido se dirigen a los poderes públicos, parece exigir un contrapeso que evite los riesgos de sometimiento a tales poderes (Divar Garteiz-Aurrecoa, 1987:75). Así, en el principio subyace el temor a que las medidas de ayuda y promoción cooperativa puedan implicar la aplicación de intensos regímenes de intervención y, con ellos, una pérdida de independencia de las cooperativas.

Buen ejemplo es la proverbial Recomendación OIT núm. 193, sobre la promoción de las cooperativas $(2002)^{16}$, cuyo punto II está plagado de exigencias respecto al papel que se pide de los gobiernos y a los que se reclama, entre otros, el establecimiento de un marco institucional que propicie la creación "rápida, sencilla, económica y eficaz"

14. Sobre ambas posturas, vid. SANTOS DOMÍNGUEZ, 2015:110-113.

15. GADEA SOLER (2012:13) señala cómo este principio no se recogió en la declaración de 1995, recuperándose tras la caída de los regímenes comunistas, y recalca que se incluye la posibilidad de convenios con otras organizaciones. Véase también MACÍAS RUANO, 2014:334 y ss.

16. En adelante, R 193. Disponible en https:/www.ilo.org/dyn/normlex/es/f?p=NORMLEXPUB:12100:0::NO::P12100_ILO_code:R193 
de cooperativas; facilitar la adhesión a estructuras cooperativas; medidas de apoyo a las actividades de cooperativas dirigidos s objetivos de política económica y social tales como el fomento del empleo, la integración de grupos desfavorecidos o en riesgo de exclusión, etc. a través de medidas diversas (subvenciones, exenciones fiscales, créditos, ventajas en la contratación pública...); promover la educación y formación en materia de principios y prácticas cooperativos en los distintos niveles de enseñanza...

Ahora bien, una lectura detenida de esta R193 permite advertir el difícil equilibrio exigido a los poderes público y que sitúa su papel entre el fomento y el control, a los que se añade la preservación de la autonomía cooperativa como cierre de esta cuadratura del círculo.

Veamos algunas expresiones literales de la R193. Partiendo de que los gobiernos deberían establecer una política y un marco jurídico favorables a las cooperativas $y$ compatibles con su naturaleza y función, e inspirados en los valores y principios cooperativos", se pide de ellos:

- "Prever la adopción de medidas de supervisión de las cooperativas acordes con su naturaleza y funciones, que respeten su autonomía y sean conformes con la legislación y la práctica nacionales y no menos favorables que las medidas aplicables a otras formas de empresa y de organización social" [punto 6 c)].

- La promoción de las cooperativas, "guiada por los valores y principios" enunciados en el punto 3 R193, "debería considerarse como uno de los pilares del desarrollo económico y social nacional e internacional" [punto 7.1)]. Desde esta consideración, las políticas nacionales deberían "velar por que no se pueda crear o utilizar cooperativas para evadir la legislación del trabajo ni ello sirva para establecer relaciones de trabajo encubiertas y luchar contra las seudo-cooperativas, que violan los derechos de los trabajadores, velando por que la legislación del trabajo se aplique en todas las empresas" [punto $8.1 \mathrm{~b}$ )].

- Se incluye asimismo una lista amplia de medidas de fomento de todo tipo (dotación de servicios de apoyo en diferentes ámbitos, facilitar el acceso al crédito, diseñar mecanismos de participación y un largo etcétera).

En similar sentido la Resolución 56/114 de las Naciones Unidas adoptada por la Asamblea General de la ONU el 19 de diciembre de $2001^{17}$ alienta a los Estados miembros "a que sigan examinando, según proceda, las disposiciones jurídicas y administrativas que rigen las actividades de las cooperativas, con miras a garantizarles un entorno propicio y a proteger y promover su potencial para ayudarles a lograr sus 
objetivos", prestando atención a su papel, "aprovechando y desarrollando plenamente las posibilidades que tienen (...) de contribuir a la consecución de los objetivos del desarrollo social, en particular la erradicación de la pobreza, la generación de empleo permanente y productivo y una mayor integración social"; "fomentando y facilitando el establecimiento y el desarrollo de las cooperativas, incluso mediante la adopción de medidas encaminadas a habilitar a las personas que viven en condiciones de pobreza o pertenecen a grupos vulnerables para participar a título voluntario en la creación y el desarrollo de cooperativas"; "tomando medidas apropiadas con miras a crear un entorno propicio y favorable al desarrollo de las cooperativas fomentando, entre otras cosas, una asociación efectiva entre los gobiernos y el movimiento cooperativista"; e invitando "a los gobiernos a que, en colaboración con el movimiento cooperativista, elaboren programas para promover y fortalecer la educación de los miembros, los dirigentes elegidos y los cuadros administrativos profesionales, según proceda, y crear bases de datos estadísticos sobre el desarrollo de las cooperativas y su contribución a las economías nacionales, y mejorar las existentes”.

\section{El modelo de intervención pública en la legislación cooperativa}

\section{Esquema del marco normativo común}

La legislación cooperativa que hemos tenido hasta el momento mantiene un dibujo homogéneo que permanece en el tiempo sin apenas reflexión crítica sobre su pertinencia. Téngase en cuenta que en estos más de cuarenta ańos de etapa constitucional ha habido una importante producción legislativa con leyes autonómicas que se han sucedido en el tiempo y en las que las más recientes han servido de avanzadilla y modelo para otras, que terminan emulando las novedades más llamativas.

Un recorrido por la legislación cooperativa autonómica (histórica y vigente), permite entresacar las siguientes consideraciones previas que pueden servir para encuadrar el posterior análisis:

a) En las leyes cooperativas los preceptos dedicados a la relación Administración Pública-cooperativas apenas se mueven del esquema tradicional en el que se conjugan dos aspectos: por un lado, el principio de fomento cooperativo que, con más o menos adornos, actúa de paraguas de diversas medidas incentivadoras; por otro, el control de legalidad, materializado en medidas limitativas e interventoras de dispar intensidad y que examinaremos después. 
A esa balanza suelen añadirse ingredientes organizativos tales como la determinación del órgano competente en materia cooperativa y creación de órganos colegiados a los que se confiere funciones de representación, colaboración, consultivas, incluso de mediación en conflictos.

b) Una lectura de las exposiciones de motivos de las leyes demuestra asimismo la escasa atención prestada a los títulos que contemplan los mecanismos de intervención y fomento cooperativo, que, por lo común, se limitan a ser descritos sin mayor carga de profundidad.

No obstante, esta tónica general va encontrando atisbos que revelan una reconsideración del papel de la Administración pública en las sociedades cooperativas, de los que, aunque escasos, hay ya significativos ejemplos.

\section{Principio de fomento del cooperativismo y su materialización}

Todas las leyes cooperativas sin excepción recogen un principio general de fomento del cooperativismo que suele acompañarse de ciertas medidas incentivadoras, algunas más llamativas que reales.

No se trata solo de hilar con el mandato del art. 129.2 CE y, en su caso, el precepto estatutario de similar contenido, sino que, en ocasiones, se explicitan las razones que abonan la pertinencia de dicho fomento subrayando la importancia de la cooperación en el desarrollo económico regional, su relevancia en sectores estratégicos o por su conexión con políticas públicas diversas, señaladamente la creación de empleo ${ }^{18}$, y otros objetivos que acompañan a éste (p.ej. la corrección de desequilibrios territoriales que puede conseguirse asentando a la población en comarcas en recesión a la que alude el art. 196.4 $\mathrm{LCPA}^{19}$ ). Se muestran así, espacios de intersección donde confluyen intereses públicos y privados-cooperativos y en los que la fórmula cooperativa se erige en instrumento especialmente idóneo para la consecución de fines de interés general.

18. Algunas leyes cooperativas se remiten expresamente a tales mandatos que, por lo demás, aportan también significativa información atendiendo no sólo a su contenido sino también a su ubicación en los textos. Buen ejemplo es el art. 163 del Estatuto de Autonomía de Andalucía (EAA): bajo el rótulo "Modernización económica. Acceso a los medios de producción", el fomento de las cooperativas y otras formas jurídicas de economía social (art. 163.2 EAA) viene precedido de un apartado en el que se insta a la Comunidad Autónoma a atender a "la modernización, innovación y desarrollo de todos los sectores económicos, a fin de propiciar un tejido productivo de calidad, y, en particular, de la agricultura, de la ganadería, de la pesca y de la artesanía, a fin de equiparar el nivel de vida de los andaluces y andaluzas". No parece casual que ambas menciones compartan artículo considerando el peso del cooperativismo en todos los sectores mencionados.

19. Ley del Principado de Asturias 4/2010, de 29 de junio, de Cooperativas (LCPA). 
Sin embargo, la realidad parece ir por otros derroteros: desde una visión global del ordenamiento jurídico -y, por tanto, trascendiendo la legislación cooperativa (sea esta general o específica ${ }^{20}$ ) y abarcando la legislación concursal, fiscal, de competencia, etc.- Fajardo García (2018:157) pone de manifiesto que "la legislación no es adecuada para las cooperativas porque a excepción de las leyes dictadas expresamente para su regulación, las particularidades están ausentes del derecho español”, de manera que "(ni) es adecuado (...) ni contribuye a su fomento, sino todo lo contrario". En epígrafes posteriores se corroborará esta idea.

\section{A) Un breve apunte sobre el principio general de fomento}

La lectura de las normas deja una primera diferencia: algunas de las leyes formulan el principio general reconociendo de interés general la promoción y el desarrollo de las cooperativas y de sus estructuras de integración económica y representativa (p.ej. art. 195 LCPA); en otras se establece el mandato de fomento, aunque sin incorporar la expresión resaltada en cursiva (art. $\left.134 \mathrm{LCCa}^{21}\right)$. ¿Cabe colegir alguna conclusión de ese matiz?

A nuestro entender, no. Finalmente, todos los principios generales de fomento del cooperativismo se anudan a los mandatos constitucional y autonómicos correspondientes, y el reconocimiento del interés general de tal tarea no comporta necesariamente un plus, ni deriva en una previsión más exhaustiva de medidas de estímulo que aquellas que omiten la expresión.

Con todo, la declaración del principio demuestra el difícil equilibrio que encierra el cúmulo de ingredientes: fomento público, intervención tendente a un control de legalidad y, al tiempo, preservación de la autonomía cooperativa. Así lo demuestra la invariable "coletilla" -cuya libertad y autonomía garantiza o expresión análoga- que sirve de cierre al mencionado principio general; y que, en ocasiones, se enfatiza en preceptos posteriores con reiteración innecesaria (p.ej. art. 137.2 LCR ${ }^{22}$ que incide en lo ya proclamado en el apartado precedente, asumiendo "el compromiso de realizar una política de fomento del movimiento cooperativo y de las cooperativas que lo integran dentro del más riguroso respeto al principio de autonomía que informa estas entidades”).

20. Aunque manejamos preferentemente las leyes generales sobre sociedades cooperativas, es sabido que hay normas que regulan bien la actividad cooperativa en determinados sectores económicos, bien las cooperativas con ciertas características (p.ej. Ley 8/2006, de 23 diciembre, de Sociedades Cooperativas Especiales de Extremadura; o más recientemente, Ley 4/2019, de 31 de enero, de Microcooperativas de Illes Balears)

21. Ley 6/2013, de Cantabria de 6 de noviembre, de Cooperativas de Cantabria (LCCa).

22. Ley 4/2001, de 2 de julio, de Cooperativas de La Rioja (LCR). 
B) Las medidas de fomento previstas en las leyes cooperativas: declaraciones genéricas y medidas especiales

Dicho principio general suele acompañarse de menciones a medidas que, aunque con pretensiones de concreción, se formulan de manera excesivamente genérica, lo que dificulta, incluso imposibilita, la fiscalización de su cumplimiento. Los ejemplos son incontables, aunque la forma en que se presentan puede variar: en algunos casos se enuncian atendiendo clase de cooperativas (vgr. se fomentará la creación de cooperativas de trabajo asociado, se promoverán las cooperativas agrarias,...); otras veces, se ligan a objetivos por sectores de actividad (p.ej. art. 135.2 LCCa, que elabora un listado casi agotador: agricultura, ganadería, pesca, turismo rural, actividades culturales , artísticas, deportivas,....);o, incluso, combinando varios de los anteriores (p.ej. art. 198.2 LCPA: "Las actuaciones de promoción del cooperativismo, en especial las relativas al empleo, se coordinarán con las que se lleven a efecto en aplicación de sus programas de remoción de las desigualdades de género"). La ley extremeña, más cercana en el tiempo, incluye también sectores como el de las nuevas tecnologías de la información y comunicación (art. 177.4 LCEx ${ }^{23}$ ).

A nuestro juicio, ese tipo de declaraciones, enfáticas pero casi imposibles de verificar en la práctica, terminan siendo meros compromisos formales. Un examen riguroso exigiría recabar datos, analizarlos y, sobre todo, conectar las eventuales políticas públicas con los resultados que tales datos arrojan a fin de medir la eficacia de las medidas ${ }^{24}$.

Acompañando a esas declaraciones generales, se sitúan medidas más concretas que en muchos casos reproducen fórmulas que ya recogía la legislación histórica, siendo las más comunes aquellas de corte fiscal: consideración como mayoristas de las cooperativas, pudiendo detallar como minoristas en la distribución o venta; la no consideración como ventas de las entregas de bienes y prestaciones de servicios proporcionadas por las cooperativas a sus socios; la aplicación de precios o tarifas de mayoristas a las cooperativas de consumo, agrarias y de transporte, así como su condición de consumidores directos para abastecerse o suministrarse de terceros de productos o servicios necesarios para sus actividades; reducción de los aranceles notariales en los casos en que el instrumento público notarial venga impuesto por la legislación cooperativa... 


\section{C) Actividad de fomento relacionada con la educación cooperativa}

Típico ámbito de actuaciones de fomento es el relativo a la educación, principio cooperativo de incuestionable relevancia y que es seña de identidad desde la fundación del cooperativismo ${ }^{25}$. En documentos recientes se subraya la importancia de este principio en el contexto de una economía del conocimiento, de suerte que, combinado con el principio de interés por la comunidad, se considera que encierra gran potencial en la "triple lógica" característica del cooperativismo, esto es, la unión de las preocupaciones económicas, sociales y ambientales (Roelants, 2013:51).

La formación cooperativa se contempla desde diferentes prismas, no siempre tratados con la debida sistemática, y concretado en las siguientes actuaciones:

a) Enseñanza del cooperativismo en el sistema educativo y en sus distintos niveles (y en línea con el punto $8.1 \mathrm{f}$ ) R193).

b) Formación de dirigentes, gestores, socios y trabajadores de las cooperativas.

c) Introducción del cooperativismo en los medios de comunicación de titularidad pública (o que reciban apoyo público).

d) Coordinación de las actividades de formación cooperativa realizadas con cargo a su presupuesto.

Entre las medidas de estímulo que las leyes ubican en la parcela educativa suele integrarse otra que, a nuestro entender, no tiene en éste su lugar idóneo: nos referimos al fomento de la creación de cooperativas de enseñanza (p.ej. art. 200 c) LCPA) que, como tal, excede el mero aspecto educativo y constituye más cabalmente una de las declaraciones genéricas tratadas en el apartado anterior. No obstante, el propio Plan Estratégico de la ACI 2020-2030, incluye también la "formación de cooperativas escolares" como una de las actuaciones dentro de la promoción de la identidad cooperativa engarzado con la educación.

25. Recordemos que la Declaración sobre la identidad Cooperativa, el 5o Principio (Educación, Formación e Información) se define con las siguientes palabras: "Las cooperativas ofrecen educación y formación a sus miembros, representantes electos, administradores y empleados para que puedan contribuir con eficacia al desarrollo de la cooperativa. Asimismo, informan al público en general, en especial a los jóvenes y a los líderes de opinión, sobre el carácter y las ventajas de la cooperación”. Disponible en: https://www.ica.coop/es/cooperativas/identidad-alianza-cooperativa-internacional 


\section{D) Especial referencia al fomento en materia de contratación pública}

Son muchas las leyes cooperativas que contemplan un criterio de preferencia en la adjudicación de contratos públicos, que jugaría en situaciones de empate entre licitadores (p.ej. art. 98.6 TRLCAr $^{26}$ ).

Esta medida de fomento ha terminado, sin embargo, neutralizándose porque el entrecruzamiento de normativas dictadas con base en diferentes títulos competenciales y la colisión con otras previsiones sectoriales, obliga a poner en práctica reglas de conflictos entre normas que no siempre benefician a la legislación cooperativa. En efecto, el art. 147 la Ley 9/2017, de 8 de noviembre, de Contratos del Sector Público, por la que se transponen al ordenamiento jurídico español las Directivas del Parlamento Europeo y del Consejo 2014/23/UE y 2014/24/UE, de 26 de febrero de 2014 (LCSP), establece que los órganos de contratación podrán establecer en los pliegos de cláusulas administrativas particulares los criterios de desempate aplicables en caso de igualdad entre dos o más ofertas. Tal remisión, sin embargo, constituye un ámbito de discrecionalidad delimitado; en otras palabras, conduce a un listado cerrado que no incluye en ninguno de sus apartados la preferencia por las sociedades cooperativas $^{27}$.

Esta cuestión ya ha sido objeto de controversia, zanjada en detrimento de la previsión de las leyes cooperativas: es significativa la Resolución 97/2019, de 4 de julio, del Tribunal Administrativo de Recursos Contractuales de Castilla y León ${ }^{28}$. Aun admitiendo que, entre las medidas de fomento previstas en la ley autonómica de cooperativas se recoge el derecho preferente en casos de empate en las licitaciones públicas, se esgrimen varios argumentos que vienen a contrarrestar dicha preferencia:

De una parte, por no resultar acorde con los principios rectores de la contratación pública de igualdad y no discriminación que presiden los procedimientos de selección del contratista en conexión con el art. 18 de la Ley 20/2013, de 9 de diciembre, de garantía de unidad de mercado (LGUM). Este último, relativo a las "Actuaciones que limitan la libertad de establecimiento y la libertad de circulación”, considera

26. Decreto Legislativo 2/2014, de 29 de agosto, del Gobierno de Aragón, por el que se aprueba el texto refundido de la Ley de Cooperativas de Aragón (TRLCAr)

27. El imperativo empleado deja poco lugar a dudas, cuando se dice: "Dichos criterios de adjudicación específicos para el desempate deberán estar vinculados al objeto del contrato y se referirán a..."

28. Esta Resolución estima el recurso especial en materia de contratación interpuesto por la empresa Mantenimiento Electromédico, S.A. frente a los pliegos de cláusulas administrativas particulares y de prescripciones técnicas del contrato del servicio de mantenimiento de equipos de electromedicina de centros adscritos a la Gerencia de Asistencia Sanitaria de Segovia con inclusión de cláusulas estratégicas que favorezcan objetivos de empleo o añadan valor a la contratación pública. Disponible en: https:/www.cccyl.es/es/tribunal-administrativo-recursos-contractuales-castilla-leo/resoluciones/resoluciones-ano-2019/resolucion-97-2019 
limitativas aquellas actuaciones que se basen directa o indirectamente en el lugar de residencia del operador económico (base, a la postre, de aplicación de la legislación autonómica sobre sociedades cooperativas) o requieran su inscripción en el registro de tal territorio.

A nuestro juicio, este argumento puede tener sentido en supuestos en los que los pliegos requieran la inscripción de las cooperativas en el registro autonómico correspondiente, pero no en términos generales ante una genérica preferencia hacia las cooperativas con independencia de cuál sea su lugar de constitución, registro o desenvolvimiento principal de actividad.

Mayor problema presenta salvar la literalidad del art. 147 LCSP, por cuanto, efectivamente, este contiene una lista cerrada, sin que quepa entender que el órgano de contratación pueda ser "creativo" al redactar los pliegos de cláusulas administrativas particulares. Téngase en cuenta, además, que dicho precepto tiene carácter de legislación básica, constituyéndose así en mínimo denominador común en todo el territorio nacional, y sin que la normativa autonómica de desarrollo pueda alterarlo.

A resultas de todo ello se aprecia que la normativa cooperativa "debe ceder en favor de las previsiones de la LCSP y de la LGUM". No es difícil advertir que este pronunciamiento es trasladable a cualesquiera fórmulas similares de preferencia que emplean las leyes cooperativas autonómicas.

Por lo demás, la LCSP recoge dos modalidades de reservas de contratos (Disposición Adicional [DA] 4a y DA 48 ${ }^{\mathrm{a}} \mathrm{LCSP}$ ), así como la conocida como "acción concertada" (DA 49a LCSP), algunas de las cuales constituyen instrumentos que pueden favorecer a las cooperativas (o, al menos, a determinadas clases de ellas) ${ }^{29}$.

\section{E) Otras medidas}

A lo largo de las leyes cooperativas podemos encontrar otras medidas que dejaremos sólo apuntadas:

- Medidas de asesoramiento y apoyo a la viabilidad de proyectos cooperativos en procesos de crisis empresarial, tendentes a hacer viable el cambio de modelo de gestión empresarial para que recaiga sobre los trabajadores organizados en cooperativa (p.ej. art. 177.5 LCEx).

- Mecanismos de participación tanto en procedimientos que les afecten, como en estructuras orgánicas como medio para defender mejor sus intereses y cumplir 
más cabalmente sus funciones de representación del sector (p.ej. art. 155.3 LCC ${ }^{30}$; la representatividad institucional del movimiento cooperativo está especialmente resaltado en el art. 157.2 a) LCPV ${ }^{31}$ ). De cualquier modo, las labores de representación del cooperativismo se prevén también en otras normas sectoriales (p.ej. Ley 11/2021, de 14 de mayo de recuperación de la tierra agraria de Galicia).

- Adquisición preferente en favor de cooperativas de viviendas de promoción social de terrenos de gestión pública mediante adjudicación directa (p.ej. art. 145.5 $\mathrm{LCIB}^{32}$ ).

\section{La actividad de ordenación o intervención: las medidas de control de la legalidad}

Como supuesto contrapeso del fomento del cooperativismo, las leyes atribuyen a las Administraciones públicas importantes potestades de intervención y sanción. De menor a mayor intensidad, tenemos:

\section{A) Actividad registral}

Aunque no es del caso entrar en detalles sobre esta actividad administrativa de ordenación, recordemos que, desde la ley republicana de 1931, y por influjo del régimen de asociaciones en el que originariamente encontraron amparo las cooperativas, la normativa configuró un sistema registral de carácter administrativo que es, con variaciones, el que se ha mantenido hasta la actualidad.

Los Registros de Cooperativas se conforman con base en la mixtura de dos componentes que vienen a amalgamar el carácter administrativo y la eficacia jurídica, ingrediente éste último más que discutible atendiendo a la competencia estatal sobre "ordenación de los registros e instrumentos públicos" (art. 149.1.8ª CE).

De este modo, y al margen de su concreta ubicación en las leyes ${ }^{33}$, éstas establecen la necesaria inscripción de las cooperativas en registros autonómicos que, como

30. Ley 12/2015, de Cooperativas (Catalunya) (LCC).

31. Ley 11/2019, de 20 de diciembre, de Cooperativas de Euskadi (LCPV).

32. Ley $1 / 2003$, de 20 de marzo, de Cooperativas de Illes Balears (LCIB).

33. Las leyes cooperativas dedican, por lo general, una atención limitada a la regulación de los correspondientes Registros de cooperativas dejando a posteriores reglamentos la regulación de su organización y funcionamiento. Algunas lo integran dentro del título correspondiente a la Administración pública y las cooperativas; otras, por el contrario, hacen meras referencias a la necesaria inscripción registral. 
hemos puesto de relieve en otro lugar (Burzaco Samper, 2009:7-30), pese a ser administrativos, han ido acercándose progresivamente a la operativa del Registro Mercantil y generando no poca controversia dogmática sobre su auténtica naturaleza ${ }^{34}$. No en vano, las leyes autonómicas suelen reproducir una fórmula que viene a dotar a estos registros autonómicos de los rasgos característicos de aquel cuando se señala que "la eficacia [del Registro de sociedades cooperativas correspondiente] se rige por los principios de publicidad material y formal, legalidad, legitimación, presunción de validez y de exactitud, prioridad y tracto sucesivo" 35 .

\section{B) Inspección}

Estrechamente ligada a la potestad sancionadora ${ }^{36}$, las leyes atribuyen bien al departamento competente en materia de cooperativas bien a la Inspección de Trabajo y Seguridad Social las facultades ligadas a la inspección y que se concretan en la denuncia de la correspondiente infracción, y propuestas de sanción.

No en vano, de acuerdo con la Ley 23/2015, de 21 de julio, Ordenadora del Sistema de Inspección de Trabajo y Seguridad Social (LOITSS) entre los cometidos de la función inspectora se encuentra la "vigilancia y exigencia del cumplimiento de las normas legales, reglamentarias y del contenido de los acuerdos y convenios colectivos" en el ámbito de "Cooperativas y otras fórmulas de economía social, (...), salvo que la respectiva legislación autonómica disponga lo contrario en su ámbito

34. Queremos destacar el Dictamen 611/2001 del Consejo Consultivo de Galicia, del que fue ponente Carro Fernández-Valmayor, que expresó la peculiar caracterización del Registro de Cooperativas en los siguientes términos: "El registro de cooperativas (...) constituye una manifestación de lo que la doctrina italiana ha calificado como "Administración pública de derecho privado", una aplicación de órganos y técnicas de gestión administrativos que, si bien buscan una finalidad pública (preservar la seguridad del tráfico jurídico) lo hacen incidiendo no sólo en la esfera privada sino, además, interviniendo en la creación, modificación o extinción de derechos e instituciones privadas.

Esta circunstancia de que la Administración actúe en la esfera privada calificando un negocio privado en el que no es parte y además con la facultad de calificar jurídicamente su regularidad y validez, determina además un especial enfoque del tema registral que estamos tratando en la medida en que, con efectos en el tráfico jurídico-privado, este registro excede de ser un simple registro administrativo para configurarse (...) como un registro jurídico". Consejo Consultivo de Galicia, Dictamen núm. 611 sobre el Proyecto de Decreto por el que se aprueba el Reglamento del Registro de Cooperativas de Galicia. Fecha de emisión: 18 de noviembre de 2001, Consideración tercera (“Observaciones a la legalidad”), art. 1.

35. $V$. gr. arts. 138 LCCa. En otros preceptos se evita la referencia a la presunción de validez y exactitud, y se incluye el principio de especialidad ( $v$. gr. art. 182.1 LCEx).

36. GONZÁLEZ RÍOS y CASTRO LÓPEZ (2019:296) critican la “confusión nominal” que muestran algunas leyes cooperativas entre estos dos tipos de actividad administrativa que, aunque relacionadas, son distintas. 
de aplicación" (art. 12.1 f LOITSS); y su actuación se extiende a "las sociedades cooperativas en relación a su constitución y funcionamiento y al cumplimiento de las normas del orden social en relación a sus socios trabajadores o socios de trabajo (...), sin perjuicio de lo que establezca la legislación aplicable a la materia” (art. 19.1 f) LOITSS).

Es importante destacar que la inspección vinculada a las cooperativas ${ }^{37}$ no impide las competencias que puedan ir enlazadas al concreto sector de actividad en el que aquellas se despliegan. Por ello son comunes las salvedades acerca de las funciones inspectoras que puedan corresponder a otras consejerías en función de la legislación aplicable (vgr. financiera) o, incluso, reglas específicas sobre la eventual concurrencia de inspecciones distintas (p.ej. art. 151.9 LCC, conforme al cual la tramitación de los expedientes sancionadores iniciados con base en un acta de la Inspección de Trabajo debe respetar la normativa especial de imposición de sanciones por infracciones del orden social, con las especialidades de la legislación cooperativa).

Las innovaciones que, en alguna ocasión, han pretendido incorporarse en materia de inspección revelan la dificultad del empeño: es llamativo el caso de la Ley de cooperativas de Euskadi de 1993 que, en su art. 139, reconocía facultades inspectoras a las federaciones y a la Confederación de Cooperativas de Euskadi, algo que excede de organizaciones privadas como las citadas y solo puede llevarse a cabo por funcionarios de carrera (Martínez Maneiro, 2007:42-43). La vigente ley vasca de 2019 ha eliminado dicha mención atribuyendo al departamento competente en materia de trabajo la inspección, "sin perjuicio de las facultades que otros departamentos tengan reconocidas en relación al cumplimiento de la legislación específica que les corresponde aplicar" (art. 156.4 LCE). No obstante, se reconoce asimismo un cierto rol al Consejo Superior de Cooperativas de Euskadi ${ }^{38}$, encargado de velar por el cumplimiento de los principios cooperativos. A nuestro juicio, sin embargo, no puede defenderse que dicha entidad ostente funciones inspectoras, aunque ciertamente pueda coadyuvar a las mismas ${ }^{39}$.

37. DÍEZ ACIMAS (2014:51) se plantea si resulta necesario un sistema de inspección propio y específico para las cooperativas, concluyendo que la importancia de los principios y la singular identidad cooperativa avalan un control tendente a evitar su desvirtuación.

38. De acuerdo con el art. 165. LCE, el Consejo Superior de Cooperativas de Euskadi actúa con personalidad jurídica propia, y es una entidad pública de carácter consultivo, asesor de las Administraciones públicas vascas en todo lo referido al cooperativismo y máximo órgano de promoción y difusión de éste. Esta entidad tiene composición plural, integrándose por representantes de las cooperativas, del Gobierno vasco, de las Diputaciones Forales y de la Universidad del País Vasco.

39. Así se desprende de la dicción del art. 165.2 c) LCE cuando le atribuye la función de "Colaborar con la Administración en orden a la difusión y cumplimiento de lo previsto en la presente ley y, en especial, de los 
(pp. 97-134)

\section{C) Régimen sancionador}

Constituye una porción sustancial de los títulos sobre Administración Pública y Cooperativismo; circunstancia que se explica desde las exigencias derivadas de los principios de legalidad y tipicidad que presiden la potestad sancionadora (art. $25 \mathrm{CE}$ ).

Asumida con naturalidad (posiblemente por la inercia de la legislación histórica), cabe preguntarse por qué las sociedades cooperativas están sometidas a la actuación administrativa punitiva cuando otras empresas, por el simple hecho de estar bajo otra forma jurídica, no se les aplica esta potestad extrema. Conviene aclarar que no nos referimos al régimen sancionador por razón de actividad, porque también éste se cierne sobre las cooperativas. Aludimos al régimen sancionador por el hecho de ser cooperativa y que comporta que las Administraciones públicas competentes se erigen en garantes de las reglas dadas a la cooperación ${ }^{40}$.

En trabajos previos hemos defendido la necesidad de reflexionar sobre si tiene sentido este rol (Burzaco Samper, 2015b), máxime cuando los regímenes sancionadores no siempre se han caracterizado por cumplir cabalmente el principio de tipicidad.

Varias son las consideraciones que, sintéticamente, queremos subrayar:

a) Las leyes cooperativas han ido depurando su régimen sancionador a medida que aparecían nuevas versiones, hecho que se advierte en un doble sentido: por una parte, se han aquilatado los tipos infractores, concretando de manera más precisa las conductas y evitando tipos excesivamente abiertos que dejaban en manos del aplicador la apreciación de la comisión de la conducta infractora. Ese mismo proceso se percibe también en las sanciones, en cuanto los legisladores separan los grados de la sanción -mínimo, medio y máximo- y las horquillas de sanciones aplicables a dicha graduación.

b) No obstante lo anterior, siguen encontrándose tipificaciones discutibles por su vaguedad y es frecuente el recurso a la tipificación residual en el caso de las infracciones leves ${ }^{41}$.

principios cooperativos. En concreto, velará por el cumplimiento de los principios cooperativos, especialmente el control democrático y la participación económica de las personas socias, sin perjuicio de las funciones inspectoras que corresponden al Gobierno Vasco o a otras administraciones públicas, de conformidad con el articulo 147.1 " (cursiva nuestra).

40. Recordemos que la competencia sancionadora es instrumental respecto de la material con la que se anude, lo que explica que cada ley autonómica recoja el régimen sancionador.

41. Las tipificaciones residuales son aquellas que se elaboran por vía negativa, esto es, aquellas que no entran en otras categorías previamente descritas en la ley sancionadora. Este tipo de tipificación puede encontrarse, sobre todo, respecto de las infracciones leves y, pese a su cuestionable ajuste al principio de tipicidad, han recibido el aval del TC [STC 341/1993, de 18 de noviembre]. 
Así, es habitual que se califiquen como infracciones leves "el incumplimiento de las obligaciones y la vulneración de las prohibiciones impuestas por [esta ley], que no supongan un conflicto entre partes, no interrumpan la actividad social y no puedan ser calificadas de graves o muy graves" (arts. 205 LCPA, 140.1.1 LCR); o, más sencillamente, "incumplir las obligaciones establecidas por la presente ley que no estén tipificadas como infracciones graves o muy graves” (art. 150.1 b) LCC).

Sin embargo, otras tipificaciones de infracciones leves están mejor delimitadas (vgr. art. 160.3 d) LCCM $^{42}$, que establece "cualesquiera otras que afecten a obligaciones de carácter formal o documental y que no estén tipificadas por [la ley] como graves o muy graves").

c) Según la jurisprudencia constitucional la competencia autonómica para establecer los regímenes sancionadores en los ámbitos sectoriales de su titularidad, está sometida a determinados límites (STC 87/1985, de 16 de julio): por un lado, el exigible respeto a las garantías constitucionales del derecho sancionador (art. 25 $\mathrm{CE}$; por otro, las disposiciones sancionadoras no deben introducir diferencias irrazonables y desproporcionadas al fin perseguido respecto del régimen aplicable en otras partes del territorio nacional, conectándose así con el principio de igualdad y la competencia estatal sobre "regulación de las condiciones básicas que garanticen la igualdad de todos los españoles en el ejercicio de los derechos y en el cumplimiento de los deberes constitucionales" (art. 149.1.1 a CE).

Estas lógicas fronteras se desdicen en la práctica. El hecho de que haya múltiples legisladores propicia que, en la comparativa, hallemos diferencias chocantes. Sin entrar en la diferente tipificación de infracciones (conductas que en una ley se consideran infracción grave y muy grave en otra; o conductas constitutivas de infracción en una Comunidad Autónoma y no en otra), pongamos sólo algunos ejemplos llamativos:

- Plazos prescripción, tanto de infracciones como de sanciones: p. ej. en la normativa catalana todas las sanciones prescriben en el plazo de 3 años a contar

Mayores problemas plantean las cláusulas sancionadoras residuales por las que se castiga genéricamente la infracción de los deberes contemplados en una norma, en cuanto remitan su concreción a normas reglamentarias (p.ej. Tipificar como infracción leve "las vulneraciones de obligaciones y prohibiciones de [esta] ley y su normativa de desarrollo no tipificadas como infracción grave o muy grave"). Tales remisiones a normas infralegales suelen considerarse inconstitucionales por incompatibles con el art. 25.1 CE, "pues en modo alguno puede la ley habilitar o remitir al reglamento para la configuración "ex novo" de obligaciones o prohibiciones cuya contravención dé origen a una infracción sancionable" [SSTC 341/1993, de 18 de noviembre; 60/2000, de 2 de marzo; 26/2002, de 11 de febrero; 13/2013, de 28 de enero]

42. Ley 11/2010, de 4 de noviembre de 2010, de Cooperativas de Castilla-La Mancha (LCCM). 
desde su firmeza (art. 152.2 LCC), mientras en la mayor parte de leyes cooperativas se distinguen distintos plazos de prescripción de la sanción en función de su gravedad (lo más común: seis meses o un año para sanciones por infracciones leves, dos años para graves y tres años para muy graves). En aplicación de la LCCa, las infracciones leves prescriben a los tres meses, las graves a los seis y las muy graves al año, sin embargo, en otras normas, las leves prescriben al año, las graves a los dos años y las muy graves, a los tres años (p.ej. art. 187.1 LCEx); o a los seis meses (infracciones leves), un año (graves, o dos años (muy graves) (p.ej. art. 160.4 LCPV). Las diferencias no son menores.

- Sanciones: aunque se advierte interés por determinar mejor las sanciones, distinguiendo su graduación en tres niveles -mínimo, medio y máximo-, se aprecian diferencias (algunas, importantes) en sus cuantías. P.ej. una sanción muy grave puede alcanzar en Catalunya o en Extremadura los 60.000 euros (art. 151.1 c) LCC; art. 186.1 c) LCEx), mientras en otras normativas el máximo alcanza los 35.000 euros (art. $147.1 \mathrm{c}$ ) LCCa) y en algunas apenas se superan los 30.000 euros (p.ej. art. 141.1 LCR; art. 160.1 LCPV; art. 138.3 c) LCCL ${ }^{43}$; art. 148.3 c) LCIB).

Las diferencias en las sanciones se extienden asimismo a las accesorias, que, se prevén en algunas leyes, pero no así en otras. Entre estas sanciones accesorias podemos encontrar la prohibición de contratar con las administraciones públicas o la exclusión de la posibilidad de obtener cualquier tipo de ayuda, bonificación o subvención de carácter público (p.ej. art. 151.5 LCC).

También pueden apreciarse algunas diferencias en los criterios de graduación y su aplicación ${ }^{44}$.

d) Como ya denunciamos anteriormente, algunos tipos pecan de excesiva generalidad y, aunque el TC entiende compatibles tales expresiones con el principio de tipicidad, se dificulta su aplicación (así, las infracciones, generalmente graves o muy graves, que tipifican la transgresión de los principios cooperativos sin mayor concreción; p.ej. art. 160.5 a) LCCM).

43. Ley 4/2002, de 11 de abril, de Cooperativas de la Comunidad de Castilla y león (LCCL).

44. Por ejemplo, es discutible la previsión del art. 151.4 LCC, según el cual si los criterios de graduación descritos en la ley no se aprecian relevantes, la sanción se impondrá en su grado medio. Con mayor acierto otras normativas, con una regla análoga, determinan la aplicación de la sanción en su grado mínimo. 


\section{D) La descalificación $n^{45}$}

Estamos ante una medida que presenta perfiles algo confusos, por cuanto bien se conecta con las causas de disolución de la sociedad cooperativa, bien se configura como sanción máxima aplicable a infracciones graves y/o muy graves (con o sin circunstancias de agravación, dependiendo de la normativa aplicable).

En este último caso interesa destacar que el modo en que se tipifican algunos supuestos de descalificación es manifiestamente mejorable: su carácter de sanción máxima propicia que el legislador se lance a adjetivar a través de calificativos contundentes pero cuya apreciación complica. P.ej. art. 161.1 a) LCPV establece como causa de descalificación "la comisión de cualesquiera infracciones de las consideradas como muy graves (...) cuando provoquen o puedan provocar perjuicios económicos o sociales o que supongan vulneración reiterada y relevante de los principios cooperativos". Aunque cambia el término "esencial" (previsto en la ley anterior y sustituido ahora por relevante), no se evita la indeterminación del concepto y las dificultades para deslindar cuándo hay una vulneración relevante de los principios cooperativos.

Por lo común, la descalificación comporta la consecuencia extrema de la disolución de la cooperativa (vgr. art. 141.3 LCG), si bien algunas leyes cooperativas contemplan la posibilidad de transformación de la misma en cualquier otro tipo social admitido en Derecho (vgr. art. 189.3 LCEx).

\section{E) La intervención temporal de sociedades cooperativas}

La intervención temporal de cooperativas se ha definido como "la facultad que la Ley atribuye a la Administración para actuar en el ámbito interno de una cooperativa; es decir, es la capacidad que la Ley le otorga para introducirse directamente en sus órganos sociales, mediatizando bajo su control la actividad de los mismos en un espacio de tiempo determinado" (GADEA SOLER, 1999:330).

Estamos así ante el trasunto en el ámbito cooperativo de la potestad administrativa de intervención de empresas ${ }^{46}$, una técnica constitucionalmente prevista en el art. 128.2 CE y que comporta la publificación de la gestión empresarial (Hernando Delgado, 1982:713) con diverso nivel de intensidad.

Su carácter excepcional se manifiesta en dos aspectos: por un lado, en sus presupuestos habilitantes, que remiten a circunstancias de especial gravedad que servirían de aval para la injerencia pública con base en la salvaguarda del interés general; por 
otro, por los efectos, siquiera temporales, de una medida que comporta la limitación del derecho a la libertad de empresa (art. $38 \mathrm{CE}$ ) y una quiebra de la autonomía cooperativa.

Esta potestad no siempre se ha previsto en la normativa cooperativa y aunque algunos han querido ver su antecedente más remoto en los arts. 52 y 118 del Reglamento para la aplicación de la Ley de Cooperativas de 1931, su precedente cabal está en el art. 93 del Reglamento de Cooperación de 1971 y art. 136 del Reglamento de $1978^{47}$.

En la legislación estatal y autonómica esta figura -tampoco siempre contempladaha tendido a desaparecer al albur de las reformas normativas ${ }^{48}$. Actualmente regulan la intervención temporal de la cooperativa la legislación aragonesa (art. 96 TRLCAr) y vasca (art. $162 \mathrm{LCPV})$, si bien con algunas diferencias:

a) La norma de Aragón se remite a la concurrencia de "circunstancias que pongan en grave peligro intereses de los socios o de terceros", locución que permitiría entender comprendidas tanto aquellas de origen interno a la entidad cooperativa, como otras, de procedencia externa, que llevan a la situación antedicha.

No ocurre lo mismo en la ley vasca que, manteniendo el tenor literal de normas precedentes, liga la intervención temporal a "irregularidades en el funcionamiento de una cooperativa", como consecuencia de las cuales, "se den circunstancias que aconsejen la adopción de medidas urgentes para evitar que puedan lesionarse gravemente intereses de las personas socias o de terceras personas no socias". Aquí, por tanto, han de darse dos requisitos cumulativos que entroncan con el funcionamiento interno de la cooperativa, aunque a nuestro juicio no necesariamente con la comisión de infracciones tipificadas en la ley.

b) En cuanto a las medidas de intervención, y empleando la terminología más común entre la doctrina, éstas pueden ser:

47. La legislación republicana circunscribía la intervención gubernativa a dos supuestos singulares, sustancialmente distintos a los contemplados en la normativa posterior: a) nombramiento de uno o varios comisarios encargados de ultimar las operaciones de liquidación cuando éstas no se hubieren iniciado en determinado plazo o fueran demoradas maliciosamente; b) en cooperativas escolares, en el caso de perturbación estudiantil y a los solos efectos de evitar ésta o el daño producido a los intereses de la cooperativa.

48. Así ha ocurrido en la legislación estatal, que contemplaba la intervención temporal en el art. 152 de la Ley 3/1987, de 2 de abril, General de Cooperativas, eliminándola en la Ley 27/1999, de 16 de julio, de Cooperativas. Algo después, la Ley 14/2011, de 16 de diciembre, por la que se modifica la LCG, también la suprimió "dada la complejidad y escasa operatividad de la medida". Más recientemente, la regulación extremeña, que preveía la intervención en el art. 181 de la Ley 2/1998, de 26 de marzo de Sociedades Cooperativas de Extremadura, la ha hecho desaparecer en el texto vigente de 2018. 
- Intervención-Presidencia: basada en el nombramiento de uno o más interventores con facultades para convocar, establecer el orden del día y presidir la Asamblea General ${ }^{49}$.

- Intervención-Aprobación: consistente en la intervención de los órganos de la cooperativa cuyos actos sólo serán válidos en la medida en que cuenten con la aprobación de los interventores. Es, por tanto, algo más que un poder de veto por cuanto se condiciona la validez de los actos a dicha aprobación, siendo en otro caso nulos de pleno derecho.

- Intervención-Sustitución: estamos ante la medida de mayor intensidad que implica la suspensión temporal de los administradores de la cooperativa, con nombramiento de uno o más administradores provisionales. Esta modalidad se encuentra prevista en la ley vasca, no así en la aragonesa.

Indudablemente, como cualquier medida limitativa, su ejercicio debe estar presidido por los principios de proporcionalidad y favor libertatis, hoy recogidos en el art. 4.1 de la Ley 40/2015, de 1 de octubre, de Régimen Jurídico del Sector Público $^{50}$.

c) No debe confundirse la intervención temporal, con las características comentadas, de las medidas cautelares que algunas leyes contemplan y que se ligan a la incoación del procedimiento sancionador. Así, algunos preceptos prevén la posibilidad de que el órgano competente para resolver el expediente sancionador pueda adoptar en cualquier momento y de manera motivada, determinadas medidas tendentes a asegurar la eficacia de la resolución, tales como: i) la designación de una o más personas con la facultad de convocar la Asamblea General, establecer su orden del día y presidirla; ii) someter las cuentas a informe de expertos independientes, designándolos; iii) suspender el abono de subvenciones concedidas a la cooperativa (art. 188.3 LCEx; art. 122.2 LCA $^{51}$ ).

49. Sobre la duplicidad de esta modalidad con la facultad judicial de convocar Asambleas, ordinarias o extraordinarias, vid. PAZ CANALEJO, 1994:904.

50. Bajo el rótulo "Principios de intervención de las Administraciones Públicas para el desarrollo de una actividad", se establece: "1. Las Administraciones Públicas que, en el ejercicio de sus respectivas competencias, establezcan medidas que limiten el ejercicio de derechos individuales o colectivos o exijan el cumplimiento de requisitos para el desarrollo de una actividad, deberán aplicar el principio de proporcionalidad y elegir la medida menos restrictiva, motivar su necesidad para la protección del interés público así como justificar su adecuación para lograr los fines que se persiguen, sin que en ningún caso se produzcan diferencias de trato discriminatorias. Asimismo deberán evaluar periódicamente los efectos y resultados obtenidos".

51. Ley 14/2011, de 23 de diciembre, de Sociedades Cooperativas Andaluzas (LCA). 


\section{4. ¿Hacia una reconsideración del papel de las Administraciones Públicas? Algunos tímidos indicios y sus paradojas}

Anticipábamos en líneas previas que algunas normas deslizan afirmaciones en las que podemos advertir señales de posibles cambios o, cuando menos, de reflexión sobre algunos mecanismos de intervención pública en las cooperativas.

Dicho esto, y aun valorando positivamente estos destellos de cambios futuros, lo cierto es que no siempre guardan la exigible coherencia con el articulado al que anteceden:

En el caso de la ley extremeña, la Exposición de Motivos afirma que el régimen sancionador se ha reducido a la mínima expresión y que "en un futuro está, probablemente llamado a desaparecer". Ciertamente el cuadro de infracciones presenta un recorte importante: por un lado, por la reducción de los tipos infractores; por otra, porque muchas de las infracciones que la ley anterior tipificaba como muy graves, han pasado a ser graves. Sin embargo, en contraste con la tipificación concreta de conductas como infracciones leves, la actual ley opta por un modelo residual siempre de más difícil aplicación práctica. Por lo demás, cumple reconocer que la eliminación absoluta del régimen sancionador no es tarea sencilla, por cuanto subyace la pretensión de los legisladores de evitar las falsas cooperativas: así, el propio legislador extremeño reconoce que se ha incidido en la regulación de la descalificación considerando que sus efectos "son lo suficientemente potentes como para desincentivar las falsas cooperativas". Y ello explica que, entre las causas de descalificación, se incluya la imposición de sanción por infracción grave o muy grave (art. 189.1b) LCEx). En este sentido, la predicción de que el régimen sancionador esté llamado a desaparecer es más el anuncio de que algo empieza a moverse en el ánimo del legislador, aunque lógicamente es un proceso que requerirá su tiempo.

También en esa dinámica de reconsideración del papel de las Administraciones Públicas parece estar la ley vasca (normativa que, en muchas ocasiones, ha actuado de avanzadilla en la implementación de cambios significativos), donde podemos leer:

(...) se suscita, en el momento actual de desarrollo de las cooperativas vascas, la necesidad de innovar aspectos que han quedado en cierta manera obsoletos. Uno de ellos, importante por el papel de "policía» que desempeña la Administración, es el referido a las infracciones -con la correspondiente función de inspección-y sanciones, por contravenir la legislación cooperativa sustantiva vasca. Con este objetivo, se preveía en 1993 la necesidad de regular un procedimiento sancionador especifico, que, sin embargo, hasta el día de hoy no se ha producido. Cuanto antecede exige abordar el régimen de infracciones y sanciones actualmente previsto en los artículos 139 y 140 de la Ley 4/1993, no ya para su desarrollo, sino 
para su revisión, como política legislativa en esta materia, después de la prolongada vigencia de la Ley 4/1993; sobre todo, teniendo en cuenta la evolución empresarial y societaria de las cooperativas vascas durante dicho periodo, por una parte y por otra, que la actual tipificación de infracciones y correspondientes sanciones, es tributaria de una regulación anclada en una visión de tutela y supervisión administrativas que se entiende necesario revisar.

Se considera que el papel de la Administración ha de focalizarse en los aspectos fundamentalmente cooperativos, como son la participación de las personas socias o la adopción de acuerdos-ejercicio real de la democracia cooperativa-, y la solidaridad-fondos irrepartibles o aplicaciones-, $y$ desprenderse de otros aspectos puramente formales u operativos -comunes, por otra parte, con el resto de sociedades que operan en el mercado- que no se hallen vinculados directamente con aquellas cuestiones que son sustanciales de la cooperativa y la hacen diferente del resto de sociedades. Es decir, aquellos aspectos que hacen a este tipo de empresas de "interés social», que es lo que legitima la intervención pública.

Reflexión ésta muy sugestiva y plausible, si no fuera por la propia vaguedad del concepto "interés social" 52 y porque una posterior lectura del articulado muestra que la proclamada revisión apenas se ha iniciado. Hemos visto, por ejemplo, cómo la ley vasca es una de las dos que mantiene la intervención temporal de sociedades cooperativas y algunas de sus infracciones mantienen tipos genéricos que podían haberse mejorado en su redacción.

\section{Conclusiones}

El principio general de fomento del cooperativismo muestra la tensión que provoca el siempre difícil equilibrio entre las actuaciones de estímulo que pretenden proteger la fórmula cooperativa y expandirla y la necesaria preservación de la autonomía de las cooperativas y sus estructuras de integración. Dicha autonomía constituye un principio de su identidad que, sin embargo, ha tratado de conciliarse con la histórica reclamación a los poderes públicos tanto de un marco normativo idóneo y respetuoso con su singularidad (y, en todo caso, no disuasorio) como de actuaciones de diverso signo que propicien el desarrollo del movimiento cooperativo.

Con todo, las leyes cooperativas encierran previsiones relativas al fomento cooperativo que no siempre son susceptibles de materialización: bien porque constituyen 
meras declaraciones grandilocuentes que no encierran compromisos concretos y exigibles; bien porque las medidas de la legislación sectorial entran en conflicto con tales previsiones $(v \cdot g r$. en materia de contratación pública), la realidad es que las medidas previstas en las leyes cooperativas se convierten muchas veces en un "brindis al sol", vacío de contenido.

La presencia pública en las sociedades cooperativas, sea en labores de estímulo sea a través de fórmulas limitativas, cruza constantemente los diferentes títulos de intervención atribuidos a las Administraciones públicas actuantes. Así, la inspección cooperativa a veces coincide (y otras, no) con la inspección de trabajo, la financiera...; el fomento del cooperativismo se enfatiza y merece mayor consideración si, además, favorece otras políticas públicas (integración de colectivos en riesgo de exclusión social, igualdad de género...); a las sanciones previstas en la legislación cooperativa pueden sumarse las derivadas de infracciones recogidas en todo tipo de legislación sectorial, sea estatal o autonómica...Ese constante entrecruzamiento genera una tela de arańa que termina haciendo difusos los contornos de los títulos competenciales que entran en juego. Cabría argumentar que este escenario es repetitivo en nuestro Estado compuesto. Sin embargo, no lo es tanto que uno de los factores de la intersección venga dado por la forma jurídica de la entidad que desarrolla la actividad.

Un análisis realista de la legislación cooperativa y de los elementos de intervención pública exige, por tanto, la visión del ordenamiento jurídico como un todo global de modo que la legislación cooperativa, ya general, ya específica, se integre e interaccione con aquellas normas que disciplinan otras parcelas de actividad.

Reiteramos una vez más que se exige una revisión de los mecanismos previstos en las leyes ya que incorporan títulos de intervención, en ocasiones muy severos, que otorgan a las Administraciones públicas un papel de tutela difícilmente compatible con la libertad y autonomía de las cooperativas. 


\section{Bibliografía}

ALARCÓN CARACUEL, M.R.: El derecho de asociación obrera en España (18391900), Ediciones de la Revista de Trabajo, Madrid, 1975.

ALFONSO SÁNCHEZ, R.: "La reforma de la legislación estatal sobre Sociedades Cooperativas: su incidencia en las Comunidades Autónomas sin ley reguladora", Revista Jurídica La Ley, no 2, 1999, pp. 1682-1690.

ARANZADI TELLERÍA, D.: "Orígenes históricos y asentamientos ideológicos del asociacionismo económico". En: II Congreso Mundial Vasco. Congreso de Cooperativismo (AAVV.), Universidad de Deusto \& Gobierno Vasco, Bilbao, 1988, pp. 23-47.

Del ARCO ÁLVAREZ, J.L.: "Ordenamiento jurídico de la cooperación en España”. En: La empresa artesana y cooperativa a la luz de la doctrina social católica. Anales de Moral Social y Económica, Vol. 3, Centro de Estudios Sociales de la Santa Cruz del Valle de los Caídos, Madrid, 1963, pp. 199-256.

- Cooperativismo, una filosofía, una técnica, Centro Nacional de Educación Cooperativa, Zaragoza, 1977.

BURZACO SAMPER, M.: "Las dificultades inherentes a la multiplicidad normativa en materia de Sociedades Cooperativas: perspectiva registral". En: Derecho de Sociedades. Congreso UNIJÉS 2007 (aut. GINÉS CASTELLET, N. \& LLEBARÍA SAMPER, S.), Tomo II, J.M. Bosch Editor, 2008, pp. 271-295.

- : "El control de la actividad registral cooperativa: estudio crítico sobre sus dificultades e incógnitas", REVESCO. Revista de Estudios Cooperativos, n 99, 2009, pp. 7-30.

- : Cooperativismo y poder público en España. Bases históricas, fundamentos ideológico-políticos y manifestaciones de la intervención administrativa en las Sociedades Cooperativas hasta la Constitución Española de 1978, Dykinson, Madrid, 2015a. Handle: http://hdl.handle.net/11531/6554

— : "La intervención pública en las sociedades cooperativas. El inadecuado papel de las Administraciones Públicas como garantes de los principios y valores cooperativos mediante el ejercicio de la potestad sancionadora", CIRIEC-España, Revista Jurídica de Economía Social y Cooperativa, no 27, 2015b, pp. 1-40. 
La intervención pública en las sociedades cooperativas: la necesidad de revisar el modelo...

(pp. 97-134)

- : "Concurrencia competitiva, igualdad entre licitadores y discriminación positiva en las reservas de contratos: un análisis desde los conflictos", CIRIEC-España, Revista Jurídica de Economía Social y Cooperativa, no 35, 2019, pp. 169-212.

CHAVES ÁVILA, R. \& SAVALL MORERA, T.: "La insuficiencia de las actuales políticas de fomento de cooperativas y sociedades laborales frente a la crisis en España”, REVESCO. Revista de Estudios Cooperativos, no 113, 2013, pp. 61-91. DOI: https://doi.org/10.5209/rev_REVE.2014.v113.43383

COLOMBAIN, M.: Las cooperativas. Manual de educación obrera, Oficina Internacional de Trabajo, Ginebra, 1956.

CONFERENCIA INTERNACIONAL DEL TRABAJO [CIT]: Informe de la Comisión de la Promoción de las Cooperativas. Presentación, discusión y adopción, 89a reunión, 5 al 21 de junio de 2001, Organización Internacional del Trabajo (OIT), Ginebra, 2001.

DÍEZ ÁCIMAS, L.A.: "La función inspectora en materia de sociedades cooperativas", Deusto Estudios Cooperativos (DEC), no 5, 2014, pp. 43-75. DOI: https:// doi.org/10.18543/dec-5-2014pp43-75

DIVAR GARTEIZ-AURRECOA, J.: "Ley vasca de cooperativas y normativa europea”, Anuario de estudios cooperativos, Instituto de Estudios Cooperativos de la Universidad de Deusto, Bilbao, 1986, pp. 131-135.

— : Régimen jurídico de las Sociedades Cooperativas, Universidad de Deusto, Bilbao, 1987.

DRIMER, B. \& KAPLAN DE DRIMER, A.: Las cooperativas. Fundamentos, historia, doctrina, Intercoop Editora Cooperativa Limitada, Buenos Aires, 1981.

FAJARDO GARCÍA, I.G.: "El fomento de la sociedad cooperativa mediante una legislación adecuada, 40 años después”, CIRIEC-España, Revista de Economía Pública, Social y Cooperativa, no extraordinario, 2018, pp. 141-159.

GADEA SOLER, E.: "Análisis histórico-legislativo en torno a la sociedad cooperativa", Anuario de estudios cooperativos, Universidad de Deusto: Instituto de Estudios Cooperativos, 1994, pp. 101-198.

— : Derecho de las cooperativas. Análisis de la Ley 4/1993, de 24 de junio, de cooperativas del País Vasco, Universidad de Deusto, Bilbao, 1999.

— : "Delimitación del concepto de cooperativa: de los principios cooperativos a la Responsabilidad Social Corporativa", CIRIEC-España, Revista Jurídica de Economía Social y Cooperativa, no 23, 2012, pp. 1-22.

GAMERO CASADO, E.: La intervención de empresas. Régimen jurídico administrativo, Marcial Pons, Ediciones Jurídicas y Sociales, Madrid, 1996. 
GARCÍA ÁLVAREZ, B.: "Sobre la noción de interés social en las sociedades cooperativas y los principios cooperativos", CIRIEC-España, Revista Jurídica de Economía Social y Cooperativa, no 34, 2019, pp. 235-278.

GARCÍA-GUTIÉRREZ FERNÁNDEZ, C.: "La necesidad de la consideración de la Sociedad Cooperativa como entidad mercantil para la adecuada regulación", REVESCO. Revista de Estudios Cooperativos, no 66, 1998, pp. 207-234.

GARRIGUES, J.: "Qué es y qué debe ser el Derecho Mercantil", Revista de Derecho Mercantil, no 27(71), 1959, pp. 7-59.

GONZÁLEZ RÍOS, I. \& CASTRO LÓPEZ, M.P.: "Administraciones Públicas y Cooperativas". En: Tratado de Derecho Cooperativo (dir. PEINADO GRACIA, J.I. \& coord. VÁZQUEZ RUANO, T.), Tirant lo Blanch, València, 2019, pp. 267-309.

GIDE, C.: Cooperativismo, Librería y Editorial de la Federación Argentina de Cooperativas de Consumo, Buenos Aires, 1944.

HERNANDO DELGADO, J.: "La intervención pública de empresas privadas". En: Homenaje a José Antonio García-Trevijano Fos, Colegio Universitario de Estudios Financieros (CUNEF) - Instituto de Estudios de Administración Local, Madrid, 1982, pp. 709-744.

JOANIQUET AGUILAR, S.: "Historia del Movimiento Cooperativo en Cataluña”, Estudios Cooperativos, no 7, 1965, pp. 3-20.

MACÍAS RUANO, A.J.: Las sociedades cooperativas, entre la economía social y la del mercado. (análisis comparativo de las sociedades cooperativas con las de capital en función de su adecuación a los principios cooperativos y los de economía social) [Tesis doctoral, Universidad de Almería], Universidad de Almería, Almería, 2014.

MARÍN HITA, L., "Reflexiones sobre la creciente mercantilización de las cooperativas al hilo de la nueva Ley de Sociedades Cooperativas de Extremadura", REVESCO. Revista de Estudios Cooperativos, no 134, 2020, pp. 61-70. DOI: https://doi. org/10.5209/reve.69167

MARTÍN-RETORTILLO BAQUER, S.: "Esbozo histórico sobre la libertad de comercio y la libertad de industria". En: Libro Homenaje al profesor José Luis Villar Palasi (coord. GÓMEZ-FERRER MORANT, Rafael), Editorial Civitas, Madrid, 1989, pp. 697-716.

MARTÍNEZ MANEIRO, B.: "Estudio del régimen de inspección y sanción en la ley de sociedades cooperativas de Euskadi y comparativa con la regulación de esta materia en el resto de leyes cooperativas autonómicas vigentes y la ley estatal", GEZKI, no 3, 2007, pp. 41-63.

MATEO BLANCO, J: "Historia de la reforma de los principios cooperativos", Estudios Cooperativos, no 53, 1985, pp. 37-68. 
La intervención pública en las sociedades cooperativas: la necesidad de revisar el modelo...

(pp. 97-134)

MONTOLÍO, J.M.: Legislación cooperativa en la Comunidad Europea, Instituto Nacional de Fomento de la Economía Social, Madrid, 1993.

MORILLAS JARILLO, M.J.: "El ámbito de aplicación de las leyes de Sociedades Cooperativas". En: Derecho de Sociedades. Libro Homenaje al profesor Fernando Sánchez Calero, vol. 4, McGraw-Hill Interamericana, Madrid, 2002, pp. 47454812.

MOZAS MORAL, A.: "La Economía Social en sus cuarenta años de democracia", CIRIEC-España, Revista de Economia Pública, Social y Cooperativa, no extraordinario, 2018, pp. 113-117.

PANIAGUA ZURERA, M.: Mutualidad y lucro en la sociedad cooperativa, McGraw-Hill Interamericana, Madrid, 1997.

PANIAGUA ZURERA, M. \& JIMÉNEZ ESCOBAR, J.: "La necesidad de una legislación cooperativa adecuada: aspectos mercantiles, tributarios y de Derecho comunitario", CIRIEC-España, Revista de Economía Pública, Social y Cooperativa, no 81, 2014, pp. 61-93.

PASTOR SEMPERE, C.: "Notas en torno a las principales novedades de la nueva ley 27/1999, de 16 de julio, de Cooperativas", REVESCO. Revista de Estudios Cooperativos, no 69, 1999, pp. 151-182.

PAZ CANALEJO, N.: "La Constitución y las cooperativas", Documentación Administrativa, $\mathrm{n}^{\circ} 186,1980$, pp. 73-103.

— : "Comentarios a la Ley 3/1987, de 2 de abril, General de Cooperativas". En: Comentarios al Código de Comercio y Legislación mercantil especial (dir. SÁNCHEZ CALERO, F. \& ALBALADEJO, M.), Tomo XX, vol. 3, Editorial Edersa, Madrid, 1994.

POLO, A.: "Misión y sentido de la nueva ley de cooperación". Revista de Derecho Privado, no 302, 1942, pp. 16-233.

PRIETO JUÁREZ, J.A.: "El régimen económico en la vigente legislación cooperativa a la luz de los principios proclamados por la Alianza Cooperativa Internacional en 1995". REVESCO. Revista de Estudios Cooperativos, no 76, 2002, pp. 131-171.

ROELANTS, B. (coord.): Crecimiento cooperativo para el siglo XXI, Alianza Cooperativa Internacional (ACI), Bruselas, 2013.

SANTOS DOMINGUEZ, M.A.: "La relación de los principios cooperativos con el Derecho", CIRIEC-España, Revista Jurídica de Economía Social y Cooperativa, $\mathrm{n}^{\circ}$ 27, 2015, pp. 87-132.

SANZ JARQUE, J.J.: "Sobre la especialidad y contenido del moderno Derecho Cooperativo", Tribuna Cooperativa, no 17, 1974, pp. 7-16. 
- : Sobre la novedad de la institución cooperativa, Librería General, Zaragoza, 1983.

- : Cooperación, teoría general y régimen de las sociedades cooperativas, el nuevo Derecho Cooperativo, Editorial Comares, Granada, 1994.

ST. SIEGENS, J.: "Tendencias y cambios en la estructura del Movimiento Cooperativo y el papel del Estado", Documentos de educación cooperativa, no 9-10, 1970, pp. 73-91.

VALDÉS DAL-RÉ, F.: Las cooperativas de producción (Un estudio sobre el trabajo asociado), Editorial Montecorvo, Madrid, 1975.

VERGEZ SÁNCHEZ, M.: El derecho de las cooperativas y su reforma, Editorial Civitas, Madrid, 1973.

VICENT CHULIÁ, F.: "Análisis crítico del nuevo Reglamento de Cooperación (Decreto 2396/1971 de 13 de agosto, BOE de 9 de octubre)", Revista de Derecho Mercantil, no 125-126, 1972, pp. 429-537.

- : "Las empresas mutualísticas y el Derecho mercantil en el Ordenamiento español", Revista Critica de Derecho Inmobiliario, no 52(512), 1976, pp. 69-132.

— : "La legislación cooperativa autonómica: perspectiva valenciana”, REVESCO. Revista Estudios Cooperativos, no 52, 1984, pp. 11-51. 